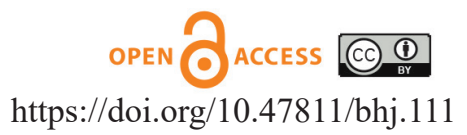

\title{
Pregnancy during a Pandemic
}

\author{
Sonam Chhoden $\mathrm{R}^{1}$
}

${ }^{I}$ Faculty of Postgraduate Medicine, Khesar Gyalpo University of Medical Sciences of Bhutan, Thimphu, Bhutan

With the first confirmed case of COVID-19 in Wuhan, Hubei Province, China in December 2019 and WHO declaring it pandemic by $11^{\text {th }}$ March 2020, more than 167 million confirmed cases are detected as of $27^{\text {th }}$ May $2021^{1}$. This increasing trend in the toll of cases is of huge concern. COVID-19 have impacted all spectrums of society and with varying and uncertain clinical presentations and outcomes. It has presented disproportionate burden for the pregnancy, one of the vulnerable groups of the population.

Pandemics preceding this current COVID-19 did not exclude this cohort of population and it is no different for the current one ${ }^{2}$. In pregnancy, due to various physiological changes leading to altered immunity it may increase the susceptibility of a pregnant woman to severe forms of COVID-19 infection ${ }^{3}$. Thus, it is imperative to understand the clinical evolution of the infection in pregnancy.

Pregnant women commonly presented with symptoms like fever, cough, dyspnea, myalgia and fatigue which was similar to non-pregnant woman and few were asymptomatic during admission so it would be advisable to screen a woman for the disease even if she has no symptom to prevent transmission of the illness ${ }^{4,5}$. In a report on woman requiring ICU admission by public health agency of Sweden for diagnosed mothers with COVID-19 revealed pregnant woman were more likely to require ICU admission making them more vulnerable than the nonpregnant woman. Although the sample analysis spanned over a month but it forewarns us to be more vigilant and to be prepared when a woman with COVID-19 is seen ${ }^{6}$. The symptomatic mothers were more prone to progress to severe form and test parameters such as increase in CRP, ALT and decrease in RBC and lymphocytes can be used as a predictor of disease severity ${ }^{7}$. Emerging evidence suggests that severe symptomatic group needs hospitalization, more oxygen dependent, management in ICUs and some mortalities. Complications are slightly more in women getting infection beyond 28 weeks of pregnancy.

With the disease being more progressive and increase in the numbers of the affected individual around the globe, the

Corresponding author:

Sonam Chhoden $R$

sonamchhodenr@gmail.com absence or minimal risk of vertical transmission of COVID- 19 was reassuring to the expectant new mothers ${ }^{8-10}$. However, finding of SARS-COV-2 in amniotic fluid and placenta tissue reported in mother who gave birth at 26 weeks of gestation would agree otherwise ${ }^{11}$. Although this is based on a single case study but the vertical transmission cannot be ruled out. Subsequently majority of the disease outcome depended on the underlying illness of the mother such as obesity and diabetes mellitus etc ${ }^{12}$ and preterm delivery being the predominant adverse outcome of COVID-19 diagnosed mother ${ }^{13}$, these factors necessitates further study to explore the need for pre-pregnancy counselling and also serve as a guide to prepare for necessary medical support for the newborn.

Breast feeding a new born by diagnosed SARS-CoV-2 mother raises concern of disease transmission. Separation from mother would compromise on baby's health which would subsequently impede the establishment of breastfeeding. This would impact on proper development and health of the baby. Thus, WHO recommends breast feeding as it outweighs the risk of contracting the disease ${ }^{14}$. The presence of lactoferrin in breast milk further supports breast feeding as it can boost baby's immunity to defend the virus infection ${ }^{15}$. However, it depends on the local or National guideline adopted to fight the COVID-19 pandemic which included policy about breast feeding.

Vaccination of pregnant and lactating mothers against COVID-19 is recommended despite not being involved in the clinical trials of any currently available vaccines. The Joint Committee on Vaccination and Immunisation (JCVI) of UK and WHO recommends for offering vaccination during anytime of pregnancy or breast feeding.

Therefore, JCVI advises that it is preferable for the Pfizer-BioNTech or Moderna mRNA vaccines to be offered to pregnant women, where available. But pregnant women above 30 years can be offered Oxford AstraZeneca vaccine. Younger ones should be given Pfizer or Moderna vaccine as the risk of thrombosis out-weighs the benefit of AstraZeneca vaccine in younger than 30 years women. COVID-19 vaccination is highly recommended to the following groups of pregnant women, with high risk medical conditions who have a greater risk of severe illness from COVID-19, who are health or social care workers at increased risk of catching COVID-19, and pregnant women diagnosed with gestational diabetes in pregnancy or pregnant women with a BMI of more than $40^{16}$.

Due to high predilection of development of severe COVID-19 in pregnant women particularly those with 
comorbidities and with no consistent contraindicating evidences of COVID-19 vaccination, it is advisable for a pregnant women and lactating mothers to be vaccinated ${ }^{17}$.

Several studies done on COVID-19 in pregnancy over the period of time have concluded with several findings and recommendations on COVID-19 pregnancy management. Regardless of these varying findings, all these studies corroborated the high susceptibility of pregnant women to this pandemic ${ }^{18}$. Undoubtedly, pregnancy is an enormous challenge for a woman, hence extending unwavering support to them is extremely essential. The universal recommendation of social distancing, wearing the mask properly and handwashing remains the main stay of fighting this pandemic even for the pregnant women.

\section{REFERENCES}

1. WHO Coronavirus dashboard. [Full Text]

2. Farrell RM, Beigi RH. Pandemic influenza and pregnancy: an opportunity to reassess maternal bioethics. Am J Public Health. 2009 Oct;99 Suppl 2(Suppl 2):S231-5. [Full Text | DOI]

3. Wastnedge EAN, Reynolds RM, Boeckel SR, Stock SJ, Denison FC, Maybin JA, et al. Pregnancy and COVID-19. Physiol Rev, 2021; 101: 37-92 [Full Text]

4. Afshar Y, Gaw SL, Flaherman VJ, Chambers BD, Krakow D, Berghella V, et al. Clinical Presentation of Coronavirus Disease 2019 (COVID-19) in Pregnant and Recently Pregnant People. Obstet Gynecol. 2020 Dec; 136(6):11171125. [PubMed | Full Text | DOI]

5. Delahoy MJ, Whitaker M, O'Halloran A, Chai SJ, Kirley PD, Alden N, et al. Characteristics and Maternal and Birth Outcomes of Hospitalized Pregnant Women with Laboratory-Confirmed COVID-19. MMWR Morb Mortal Wkly Rep 2020;69:1347-1354. [Full Text]

6. Collin J, Byström E, Carnahan A, Ahrne M. Public Health Agency of Sweden's Brief Report: Pregnant and postpartum women with severe acute respiratory syndrome coronavirus 2 infection in intensive care in Sweden. Acta Obstet Gynecol Scand. 2020 Jul;99(7):819-822. [Full Text | DOI]

7. Shmakov RG, Prikhodko A, Polushkina E, Shmakova E, Pyregov A, Bychenko V, et al. Clinical course of novel COVID-19 infection in pregnant women. J Matern Fetal Neonatal Med. 2020 Nov 29:1-7. [PubMed | Full Text | DOI]
8. Huntley BJF, Huntley ES, Di Mascio D, Chen T, Berghella V, Chauhan SP. Rates of Maternal and Perinatal Mortality and Vertical Transmission in Pregnancies Complicated by Severe Acute Respiratory Syndrome Coronavirus 2 (SARSCo-V-2) Infection: A Systematic Review. Obstet Gynecol. 2020 Aug;136(2):303-312. [PubMed | Full Text | DOI]

9. Mullins E, Evans D, Viner RM, O'Brien P, Morris E. Coronavirus in pregnancy and delivery: rapid review. Ultrasound Obstet Gynecol. 2020 May;55(5):586-592. [PubMed | Full Text | DOI]

10. Di Mascio D, Khalil A, Saccone G, Rizzo G, Buca D, Liberati $\mathrm{M}$, et al. Outcome of coronavirus spectrum infections (SARS, MERS, COVID-19) during pregnancy: a systematic review and meta-analysis. Am J Obstet Gynecol MFM. 2020 May;2(2):100107. [PubMed | Full Text | DOI]

11. Pulinx B, Kieffer D, Michiels I, Petermans S, Strybol D, Delvaux $\mathrm{S}$, et al. Vertical transmission of SARS-CoV-2 infection and preterm birth. Eur J Clin Microbiol Infect Dis. 2020 Dec;39(12):2441-5. [PubMed | Full Text | DOI]

12. Savasi VM, Parisi F, Patanè L, Ferrazzi E, Frigerio L, Pellegrino A, et al. Clinical Findings and Disease Severity in Hospitalized Pregnant Women With Coronavirus Disease 2019 (COVID-19). Obstet Gynecol. 2020 Aug;136(2):252258. [PubMed | Full Text | DOI]

13. Adhikari EH, Moreno W, Zofkie AC, MacDonald L, McIntire DD, Collins RRJ, et al. Pregnancy Outcomes Among Women With and Without Severe Acute Respiratory Syndrome Coronavirus 2 Infection. JAMA Netw Open. 2020 Nov 2;3(11):e2029256. [PubMed | Full Text | DOI]

14. Breast feeding and COVID - 19. [Full Text]

15. Peroni DG, Fanos V. Lactoferrin is an important factor when breastfeeding and COVID-19 are considered. Acta Paediatr. 2020 Oct;109(10):2139-2140. [PubMed | Full Text | DOI]

16. COVID-19 vaccines, pregnancy and breastfeeding. [Full Text]

17. COVID-19 Vaccines and Pregnancy: Conversation Guide for Clinicians. [Full Text]

18. Villar J, Ariff S, Gunier RB, Thiruvengadam R, Rauch S, Kholin A, et al. Maternal and Neonatal Morbidity and Mortality Among Pregnant Women With and Without COVID-19 Infection: The INTERCOVID Multinational Cohort Study. JAMA Pediatr. Published online April 22, 2021. [Full Text | DOI] 